\title{
Cordyceps militaris and mycelial fermentation induced apoptosis and autophagy of human glioblastoma cells
}

\author{
C-H Yang ${ }^{1,5}$, Y-H Kao ${ }^{2,5}$, K-S Huang, ${ }^{*, 3}$ C-Y Wang ${ }^{4}$ and L-W Lin ${ }^{3}$
}

This study is the first report that investigated the apoptosis-inducing effects of Cordyceps militaris (CM) and its mycelial fermentation in human glioblastoma cells. Both fractions arrested the GBM8401 cells in the G0/G1 phase, whereas the U-87MG cells were arrested at the G2/M transitional stage. Western blot data suggested that upregulation of p53 and p21 might be involved in the disruption of cell cycle progression. Induction of chromosomal condensation and the appearance of a sub-G1 hypodipoid population further supported the proapoptogenicity, possibly through the activation of caspase-3 and caspase-8, and the downregulation of antiapoptotic Bcl-2 and the upregulation of proapoptotic Bax protein expression. Downregulation of mammalian target of rapamycin and upregulation of Atg5 and LC3 II levels in GBM8401 cells implicated the involvement of autophagy. The signaling profiles with mycelial fermentation treatment indicated that mycelial fermentation triggered rapid phosphorylation of Akt, p38 MAPK, and JNK, but suppressed constitutively high levels of ERK1/2 in GBM8401 cells. Mycelial fermentation treatment only significantly increased p38 MAPK phosphorylation, but decreased constitutively high levels of Akt, ERK1/2, and JNK phosphorylation in U-87MG cells. Pretreatment with PI3K inhibitor wortmannin and MEK1 inhibitor PD98059 prevented the mycelial fermentation-induced cytotoxicity in GBM8401 and U-87MG cells, suggesting the involvement of PI3K/Akt and MEK1 pathways in mycelial fermentation-driven glioblastoma cell apoptosis and autophagy.

Cell Death and Disease (2012) 3, e431; doi:10.1038/cddis.2012.172; published online 29 November 2012

Subject Category: Cancer

Cordyceps spp., including Cordyceps militaris (CM) and C. sinensis, are a type of Ascomycete, it parasitizes insect larvae, grows, and gradually turns into a mature fruiting body. The parasitic complex of fungus and caterpillar has been used for tonics and medicinal purposes for centuries in eastern Asia. ${ }^{1,2}$ It is commonly used to treat fatigue, renal and pulmonary dysfunction, hyperglycemia, hyperlipidemia, and heart disease, such as arrhythmia. C. sinensis (known as caterpillar fungus) has long been demonstrated to possess many bioactive ingredients, such as 3'-deoxyadenosine (cordycepin), cordycepic acid, and Cordyceps polysaccharides. $^{3-5}$ Although the pharmacologically active components are still not fully resolved, at least two chemical constituents, cordycepin and cordycepic acid, have been identified and proposed as important bioactive constituents. Decades ago, because of the rarity of wild $C$. sinensis, scientists began to study the artificial cultivation of natural Cordyceps and how to produce them using fermentation technology. ${ }^{6}$ Compared with $C$. sinensis, mycelia of $\mathrm{CM}$ are easier to grow under an artificial environment, and the process of producing $\mathrm{CM}$ fruiting bodies is similar to that of other cultivated edible mushrooms. ${ }^{7}$ Previous biochemical analyses revealed that $\mathrm{CM}$ has a similar composition and pharmacological activity to C. sinensis in terms of production of cordycepin, ${ }^{8}$ and polysaccharides. ${ }^{9}$ Both $C$. sinensis and $\mathrm{CM}$ are sources of biochemicals with interesting biological and pharmacological properties, showing significant anticancer activities. ${ }^{10}$

Recently, mycelial extracts, purified nature product, submerged culture, and water extract of Cordyceps have shown a number of far-reaching medicinal effects. ${ }^{11}$ For example, mycelial extracts of Cordyceps have been found to possess diverse biological activities, including anti-inflammation, antioxidation bioactivities, and an immunostimulatory effect. ${ }^{12-14}$ Nature product of Cordyceps has shown that cordycepin, one of the main constituents of $\mathrm{CM}$, exhibits an antitumor effect in some tumor cell lines. ${ }^{15}$ Polysaccharides-peptide complexes isolated from submerged culture of $C$. sphecocephala mycelia induce apoptosis of human hepatocarcinoma HepG2 and neuroblastoma SKN-SH cells. ${ }^{16}$ In addition, water extract of $\mathrm{CM}$ may inhibit tumor cell proliferation via arresting the cell cycle at the G2/M phase and induce apoptosis through upregulation of p53, p21, and cyclin B1, as well as the activation of caspase-8, caspase- 9 , and caspase-3. ${ }^{17,18}$ In addition, animal studies have shown that CM extract effectively suppresses the growth of various tumor cell explants and angiogenesis. ${ }^{19}$

Cordyceps has only become known to most people within the past 100 years. $^{20}$ During that time, modern scientific

\footnotetext{
${ }^{1}$ Departmentof Biological Science and Technology, I-Shou University, Kaohsiung, Taiwan; ${ }^{2}$ Department of Medical Research, E-DA Hospital, I-Shou University, Kaohsiung, Taiwan; ${ }^{3}$ The School of Chinese Medicine for Post-Baccalaureate, I-Shou University, Kaohsiung, Taiwan and ${ }^{4}$ Department of Biomedical Engineering, I-Shou University, Kaohsiung, Taiwan

${ }^{*}$ Corresponding author: K-S Huang, The School of Chinese Medicine for Post-Baccalaureate, I-Shou University, No. 8, Yida Road, Jiaosu Village, Yanchao District, Kaohsiung 82445, Taiwan. Tel: + 88676151100 ext.7063; Fax: + $88676151959 ;$ E-mail: huangks@ isu.edu.tw

${ }^{5}$ The first two authors contributed equally to this work.

Keywords: Cordyceps militaris; mycelial fermentation; anticancer; apoptosis; signaling pathway

Abbreviations: MTT, 3-(4,5-dimethylthiazol-2-yl)-2,5-diphenyl tetrazolium bromide; CM, Cordyceps militaris; IC ${ }_{50}$, half-maximal inhibitory concentration

Received 16.5.12; revised 08.10.12; accepted 09.10.12; Edited by A Stephanou
} 
methods have been increasingly applied to investigate its possible large range of medicinal applications. ${ }^{21,22}$ Although the proapoptotic effect of CM has been tested in several tumor cells, there are scant reports on its efficacy in the treatment of glioblastoma, a group of heterogeneous and highly malignant primary brain tumors with survival rates that rarely exceed 12 to 15 months after diagnosis. ${ }^{23,24}$ Thus, this study aimed to investigate whether $\mathrm{CM}$ and its mycelial fermentation equally induce apoptosis of glioblastoma cells in vitro, and to elucidate the pathways involved in the CM-driven proapoptogenic signaling.

\section{Results}

Growth inhibition in cancer cell lines. To test the cytostatic effect of $\mathrm{CM}$ and mycelial fermentation on the proliferation of 3T3, MCF-7, GBM8401, and U-87MG cells, the cells were treated with different concentrations of $\mathrm{CM}$ or mycelial fermentation. After $24 \mathrm{~h}$ incubation, the cell viability and viable cell number were measured using a 3-(4,5-dimethylthiazol-2-yl)-2,5-diphenyl tetrazolium bromide (MTT) assay and Trypan blue exclusion method, respectively. The results show that treatment with $\mathrm{CM}$ or mycelial fermentation significantly reduced viability of four cell lines in a dose-dependent manner (Figure 1). This cytotoxic effect of both fractions in GBM8401 and U-87MG glioblastoma cells appeared higher than that observed in 3T3 and MCF-7 cells. The calculated half-maximal inhibitory concentration $\left(\mathrm{IC}_{50}\right)$ of CM was 1.0 and $1.2 \mathrm{mg} / \mathrm{ml}$ for GBM8401 and U-87MG cells, respectively. The $\mathrm{IC}_{50}$ of mycelial fermentation treatment was 1.6 and $2.3 \mathrm{mg} / \mathrm{ml}$ for GBM8401 and U-87MG cells, respectively.

Influence of morphological change. To observe whether $\mathrm{CM}$ and/or mycelial fermentation induces the apoptosisrelated morphological alterations in GBM8401 and U-87MG glioblastoma cells, the cells treated were stained with 4,6diamidino-2-phenylindole (DAPI) and examined under fluorescent microscope. The control cells displayed an intact and homogeneous nuclear structure. Both GBM8401 and U-87MG cells showed cell shrinkage after CM or mycelial biomass treatment, as well as cytoplasm condensation and the appearance of apoptotic bodies. In particular, the formation of chromosomal condensation was noted in both DAPI-stained cells with both $\mathrm{CM}$ and mycelial fermentation treatments (Supplementary Figure S1).

Induction of sub-G1 population and disturbance of cell cycle progression. To investigate the possible apoptogenesis in this context, glioblastoma cells were treated with $1 \mathrm{mg} /$ $\mathrm{ml} \mathrm{CM}$ or $2 \mathrm{mg} / \mathrm{ml}$ mycelial fermentation for $24 \mathrm{~h}$ and received $\mathrm{PI}$ staining and subsequent flow cytometric detection. The

Figure 1 Effects of CM and mycelial fermentation (MF) on the viability of 3Т3 fibroblasts and cancer cells. 3T3 fibroblasts (a), MCF-7 breast cancer cells (b), GBM8401 (c), and U-87MG (d) glioblastoma cells were treated with either CM or MF at a concentration of $0.5,1,1.5,2$, and $2.5 \mathrm{mg} / \mathrm{ml}$ and incubated for $24 \mathrm{~h}$. The cell viability was monitored by using MTT assay. Data are means \pm S.D. of five independent experiments $(P<0.05)$
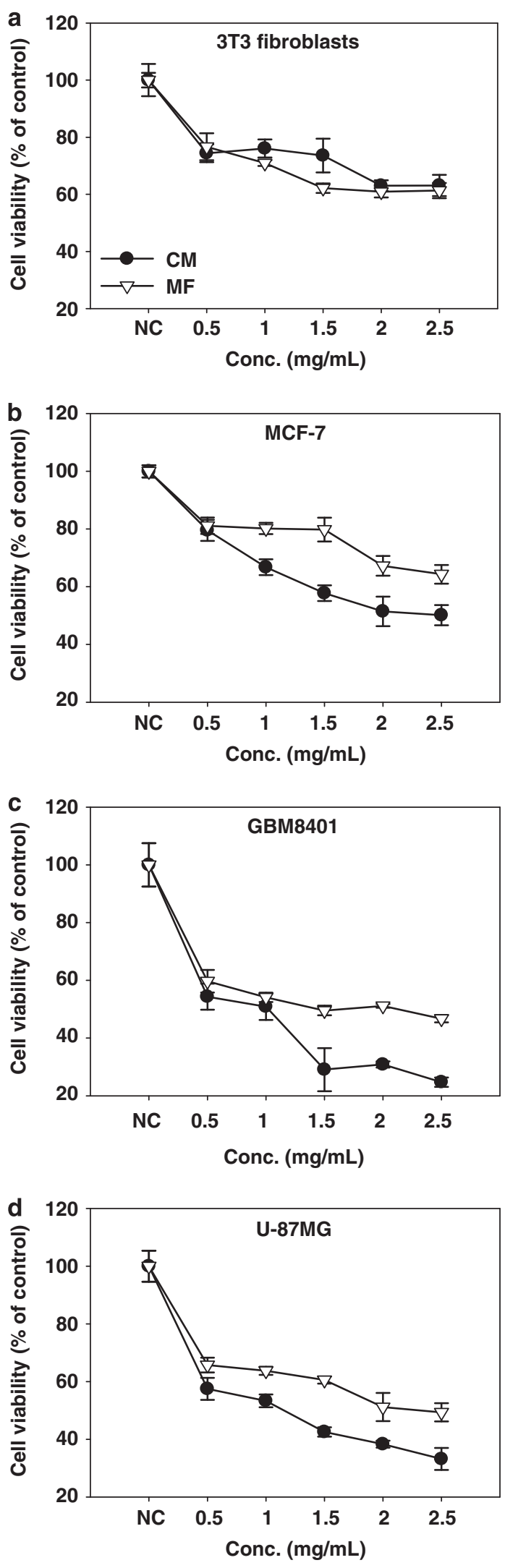
histogram analysis for sub-G1 population revealed that both $\mathrm{CM}$ and mycelial fermentation significantly increased chromosomal hypodipoidy in GBM8401 (Figure 2a) and U-87MG cells (Figure $2 b$ ). On the other hand, a kinetic analysis on early apoptotic events indicated that the mycelial fermentation of $\mathrm{CM}$ induced Annexin $\mathrm{V}$ presentation in a time-dependent manner (Figure 2c). These results suggest that the cytotoxic effects might be associated with the induction of apoptotic cell death in glioblastoma cells, and that GBM8401 cells were more sensitive to CM treatment than U-87MG cells. Moreover, the cells beyond the sub-G1 region were further used for analysis of cell cycle distribution. The data indicated that treatment with $\mathrm{CM}$ or mycelial fermentation for $24 \mathrm{~h}$ significantly increased the percentage of GBM8401 cells in the G0/G1 phase, with a concurrent decrease in the G2/M phase. However, the same treatment induced the G2/M-phase arrest and decreased the G0/G1 cell population in U-87MG cells (Table 1). These results
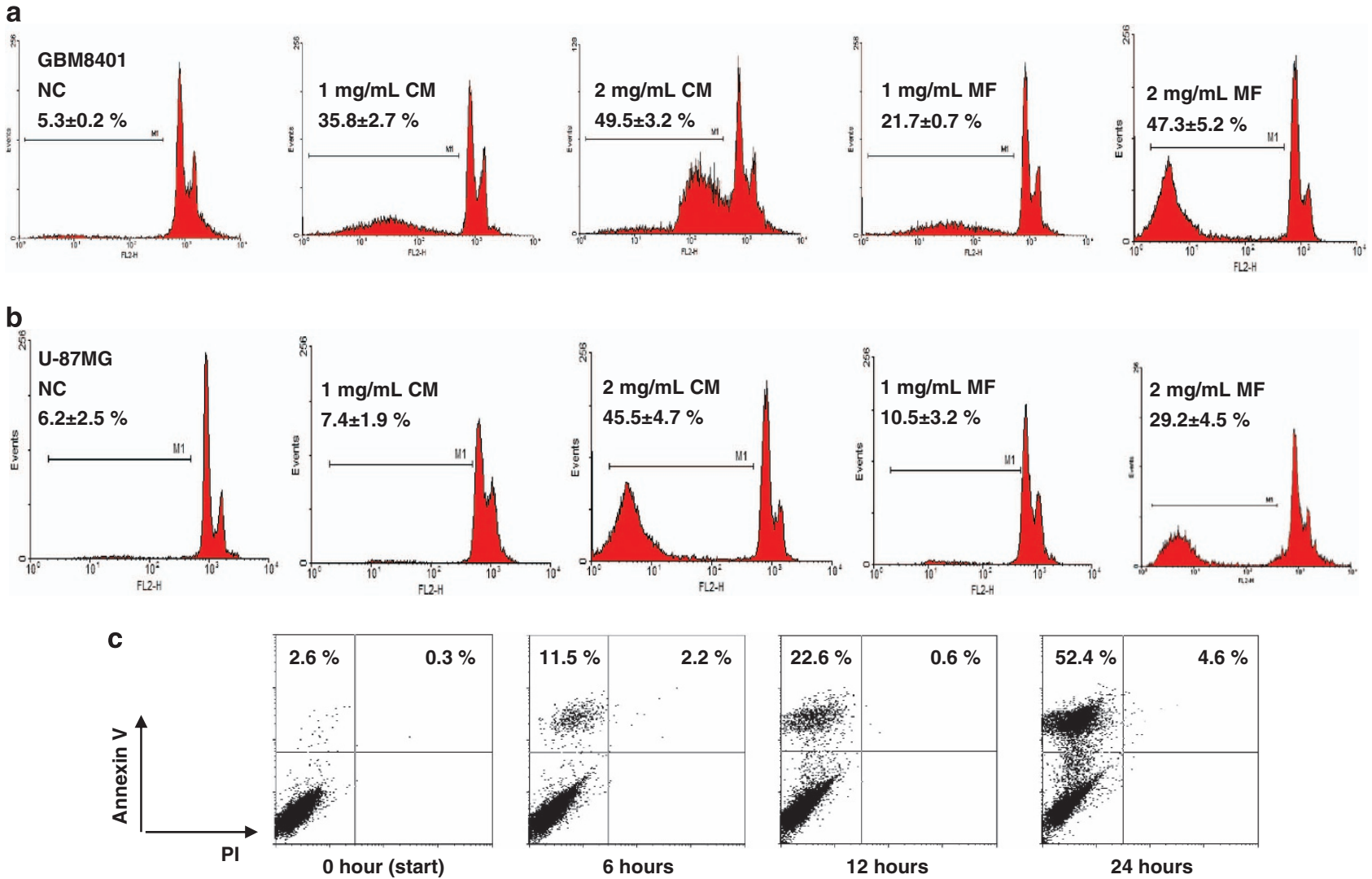

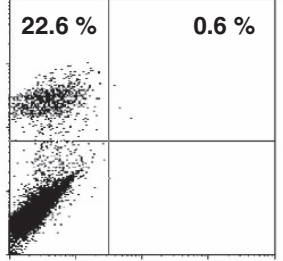

12 hours

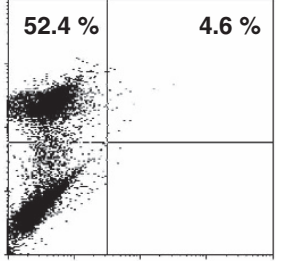

24 hours

Figure 2 Induction of hypodiploidic DNA contents and Annexin V positivity in human glioblastoma cells. Cultured human glioblastoma cells, GBM8401 (a) and U-87MG (b), were treated with either CM or mycelial fermentation (MF) for $24 \mathrm{~h}$ at the dose indicated, followed by propidium iodide (PI) staining and subsequent flow cytometric detection. The representative sub-G1 histogram profiles from three independent experiments are shown. (c) GBM8401 cells were treated with MF for indicated duration and subjected to Annexin V-FITC and PI detection by using flow cytometry. The percentage of sub-G1 and Annexin V-positive fractions in total cell populations is measured as mean \pm S.D. NC, negative control

Table 1 The modulatory effect of CM and mycelial fermentation on the cell cycle distribution of a non-apoptotic fraction of human glioblastoma GBM8401 cells and human glioblastoma U-87MG cells

\begin{tabular}{|c|c|c|c|c|c|c|c|}
\hline & \multirow{2}{*}{$\begin{array}{l}\text { Dose } \\
(\mathrm{mg} / \mathrm{ml})\end{array}$} & \multicolumn{3}{|c|}{ GBM8401 cell cycle distribution } & \multicolumn{3}{|c|}{ U-87MG cell cycle distribution } \\
\hline & & $\%$ G0/G1 & $\% \mathrm{~S}$ & $\%$ G2/M & $\%$ G0/G1 & $\% \mathrm{~S}$ & $\%$ G2/M \\
\hline C. militaris & $\begin{array}{l}0 \\
1 \\
2\end{array}$ & $\begin{array}{l}63.5 \pm 2.7 \\
70.5 \pm 3.5^{*} \\
82.3 \pm 5.8^{*}\end{array}$ & $\begin{array}{l}19.8 \pm 2.2 \\
24.7 \pm 2.3 \\
16.1 \pm 2.3\end{array}$ & $\begin{array}{c}17.5 \pm 2.4 \\
5.2 \pm 2.7^{\star} \\
1.8 \pm 2.2^{\star}\end{array}$ & $\begin{array}{l}69.4 \pm 2.8 \\
59.5 \pm 2.6^{\star} \\
45.7 \pm 3.5^{\star}\end{array}$ & $\begin{array}{r}12.4 \pm 2.4 \\
14.6 \pm 2.4 \\
9.8 \pm 3.6\end{array}$ & $\begin{array}{l}18.4 \pm 2.6 \\
26.2 \pm 3.3^{*} \\
45.3 \pm 4.3^{*}\end{array}$ \\
\hline $\begin{array}{l}\text { Mycelial } \\
\text { fermentation }\end{array}$ & $\begin{array}{l}0 \\
1 \\
2\end{array}$ & $\begin{array}{l}58.2 \pm 2.4 \\
61.9 \pm 2.3 \\
70.8 \pm 6.7^{*}\end{array}$ & $\begin{array}{l}18.9 \pm 2.2 \\
17.0 \pm 2.3 \\
21.3 \pm 3.3\end{array}$ & $\begin{array}{c}16.2 \pm 2.4 \\
16.8 \pm 2.6 \\
8.5 \pm 2.3^{*}\end{array}$ & $\begin{array}{r}72.6 \pm 2.7 \\
69 \pm 2.4 \\
45.8 \pm 2.5^{\star}\end{array}$ & $\begin{array}{r}11.7 \pm 2.3 \\
15 \pm 3.1 \\
9.8 \pm 2.9\end{array}$ & $\begin{array}{r}15.7 \pm 2.5 \\
24 \pm 2.7^{\star} \\
45.4 \pm 3.7^{\star}\end{array}$ \\
\hline
\end{tabular}

Note: GBM8401 and U-87MG cells were treated with either CM or mycelial fermentation at the indicated dose for $24 \mathrm{~h}$, followed by PI staining and subsequent flow cytometry. Data are shown as means \pm S.D. from three independent measurements.

${ }^{*} P<0.05$ using Student's $t$-test compared with respective negative control 
indicate that $\mathrm{CM}$ and mycelial fermentation differentially arrest the cell cycle progression of GBM8401 and U-87MG glioblastoma cells in the G0/G1 and G2/M phases, respectively.

Caspase activation. To determine which caspase pathway is activated in glioblastoma cells by $\mathrm{CM}$ and mycelial fermentation treatment, the cell lysates were collected and incubated with luminogenic-specific substrates for caspase3 , caspase-8, or caspase-9. The results shown in arbitrary activity unit demonstrated that both $\mathrm{CM}$ and mycelial fermentation significantly elicited caspase-3 and caspase-8 activation, but not caspase-9 activity in GBM8401 (Figure 3a) and U-87MG glioblastoma cells (Figure $3 b$ ). Furthermore, pretreatment with caspase-specific inhibitor confirmed the contribution of caspase-3 and -8 activities to cell death induction (Figure $3 c$ ). These results suggest that only the extrinsic apoptotic pathway is involved in CM-mediated glioblastoma cytotoxicity.

Regulatory disruption of cell cycle, apoptosis, and autophagy. To elucidate the molecular mechanisms underlying the cell cycle arrest and apoptotic induction by mycelial fermentation of CM, the total protein extracts from GBM8401 and U-87MG cells were subjected to western blotting. The results indicate that the upregulation of $\mathrm{p} 53$ and $\mathrm{p} 21$ proteins known for cell cycle regulation were seen dose-dependently in the GBM8401, but not the U-87MG cells exposed to CM mycelial fermentation (Figure 4a; scanned density data are referred to Supplementary Figure S2). On the other hand, the mycelial fermentation prominently downregulated Bcl-2 abundance, but upregulated Bax protein levels, which collectively might account for the apoptotic induction in both glioblastoma cells (Figure 4b). In the context of autophagic induction, a downregulation of mammalian target of rapamycin (mTOR) and upregulation of Atg5 and microtubuleassociated protein light chain II (LC3 II) were seen in GBM8401 cells (Figure 4c), suggesting the involvement of autophagy in the cell death.

Signaling profiles and the kinase activity involved in glioblastoma cell apoptosis. Western blotting data clearly demonstrated that Akt and JNK1 phosphorylation levels in $\mathrm{U}-87 \mathrm{MG}$ cells is constitutively higher than those in GBM8401 cells, whereas EKR1/2 was highly phosphorylated in both cell lines. It is worth noting that treatment with CM mycelial fermentation instantly triggered Akt, p38 MAPK, and within 10 min JNK1 phosphorylation in GBM8401 cells, while the upregulated phosphorylation all diminished within $2 \mathrm{~h}$ (Figure 5a; scanned density data are referred to Supplementary Figure S3). On the other hand, only p38 MAPK phosphorylation in U-87MG cells was enhanced by mycelial fermentation treatment, and the enhancement peaked $1 \mathrm{~h}$ after treatment. Besides, the constitutive phosphorylation of JNK1 ceased dramatically, while that of Akt was not affected (Figure 5b). Coincidently, the constitutive ERK1/2 phosphorylation in both cells was significantly suppressed by the treatment.

To determine the signaling pathways involved in the CM-induced cytotoxicity, glioblastoma cells were pretreated
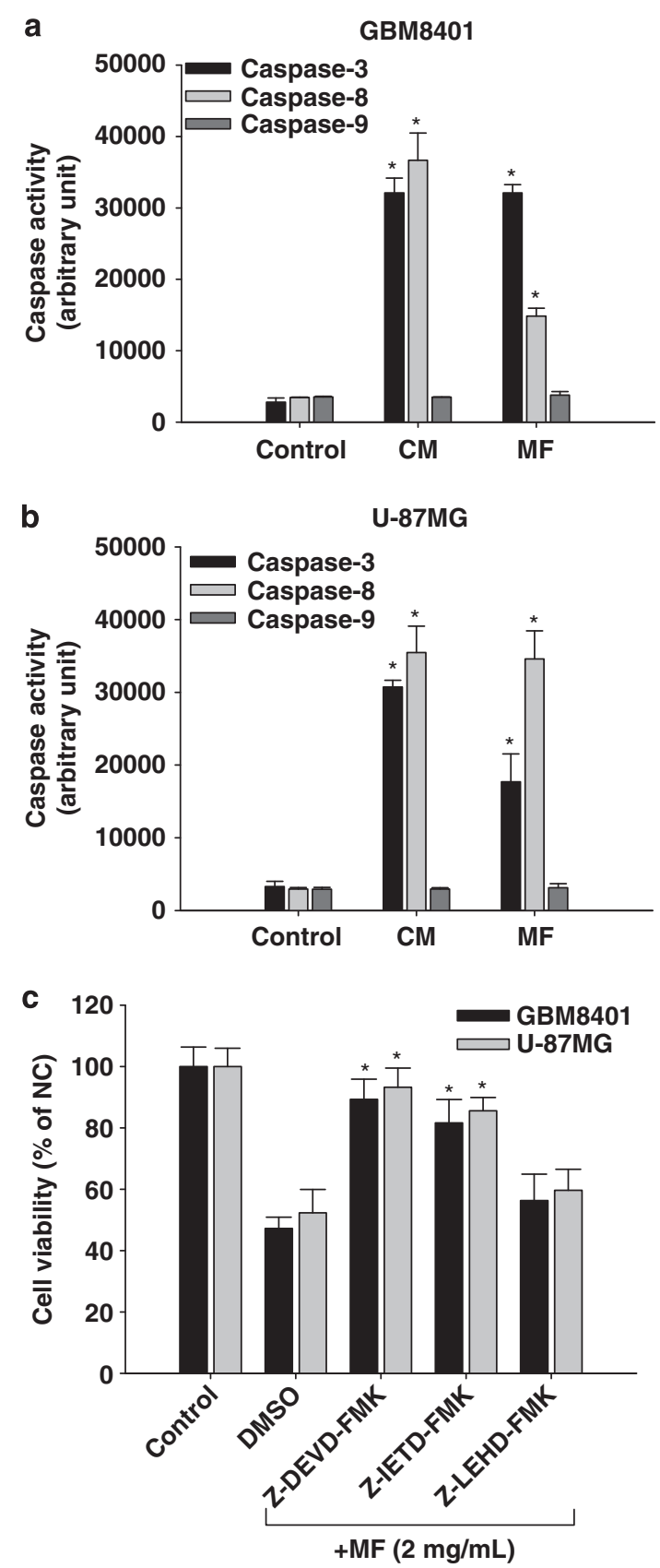

Figure 3 Caspase activation in human glioblastoma cells. Cultured human glioblastoma GBM8401 (a) and U-87MG (b) cells were treated with CM or mycelial fermentation (MF) for $6 \mathrm{~h}$ at $2 \mathrm{mg} / \mathrm{ml}$, followed by lysate collection, protein quantification, and subsequent luminometrical detection for activities of caspase-3, caspase-8, and caspase-9. Caspase activity readings were normalized by total protein. The representative data in arbitrary luminescent unit are shown as mean \pm S.D. from three independent experiments. ${ }^{*} P<0.05$, as compared with control group. (c) Both glioblastoma cells were pretreated either with Asp-Met-GlnAsp-fluoromethyl ketone (Z-DEVD-FMK), Leu-Glu-His-Asp-fluoromethyl ketone (Z-IETD-FMK), or lle-Glu-Thr-Asp-fluoromethyl ketone (Z-LEHD-FMK) peptides at $20 \mu \mathrm{M}$ for $1 \mathrm{~h}$ to block caspase-3, caspase-8, and caspase-9 activity, respectively, or with equivalent dimethylsulfoxide (DMSO) for solvent control. The cell viability after $24 \mathrm{~h}$ of MF treatment was determined by MTT assay. The representative data are shown as mean \pm S.D. from three independent experiments. ${ }^{*} P<0.05$, as compared with DMSO solvent control group. NC, negative control 


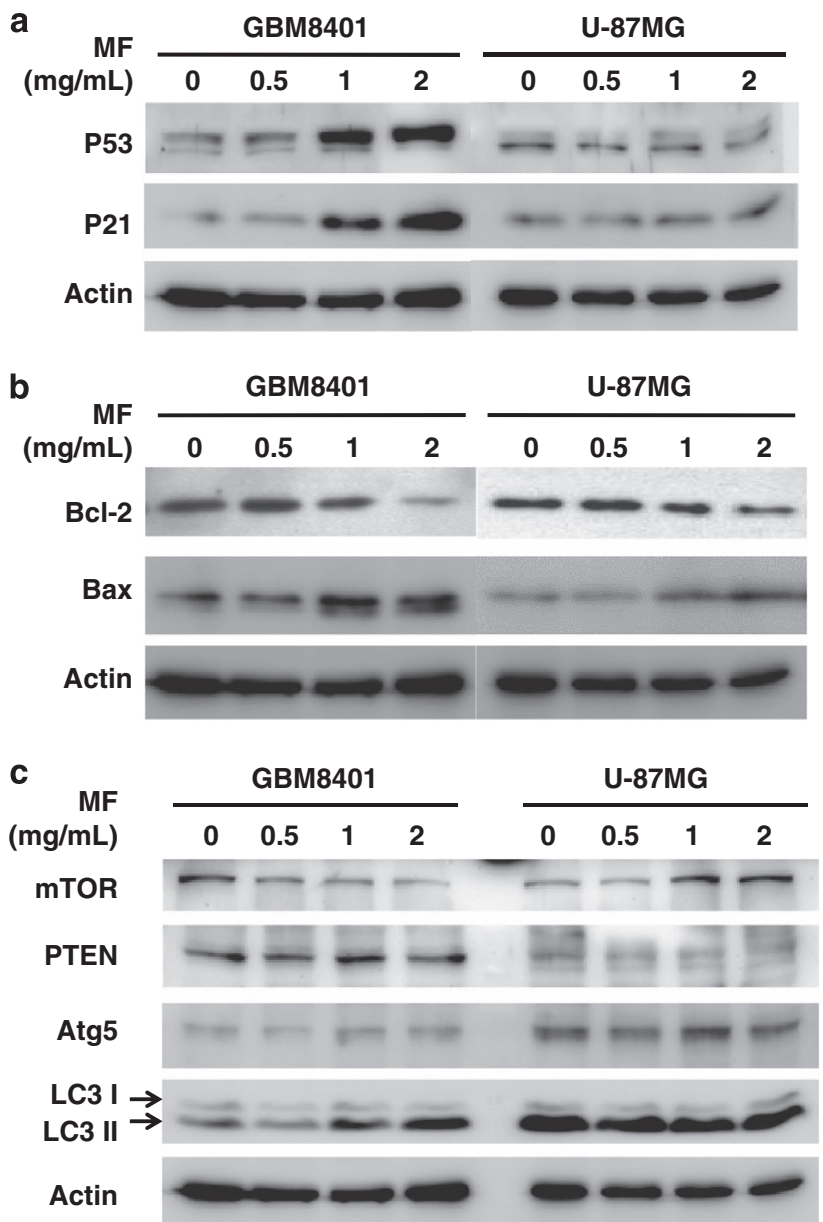

Figure 4 Modulatory effects of mycelial fermentation (MF) of CM on regulator expression of cell cycle, apoptosis, and autophagy in human glioblastoma cells. GBM8401 and U-87MG cells were treated with MF at the indicated doses for $24 \mathrm{~h}$, and the lysates were subjected to western blotting detection. (a) MF induced a significant upregulation of p53 and its downstream p21 expression in GBM8401, but not U-87MG cells. (b) MF treatment diminished the expression of antiapoptotic Bcl-2 protein, and conversely increased the abundance of proapoptotic Bax protein in both glioblastoma cells. (c) MF reduced mTOR expression but increased Atg5 and LC3 II levels in GBM8401 cells. Although MF upregulated mTOR content, MF did not affect the levels of autophagic regulators in U-87MG cells. The representative result of three independent experiments is shown

with different kinase inhibitors followed by mycelial fermentation treatment, and then the effect of kinase blockade was monitored by MTT cell viability assay. The results show that kinase inhibitor alone did not affect basal viability of glioblastoma cells, except that blockade of JNK activity remarkably suppressed U-87MG cell proliferation. Moreover, only treatment with $\mathrm{PI} 3 \mathrm{~K}$ inhibitor wortmannin significantly reversed the mycelial fermentation-induced GBM8401 cytotoxicity (Figure 6a). By contrast, the CM-induced cytotoxicity in U-87MG cells was prevented by MEK1 inhibitor PD98059, but significantly potentiated by pretreatment with JNK inhibitor SP600125 and wortmannin (Figure 6b).

\section{Discussion}

The in vitro proapoptogenic effect of fermentation of $\mathrm{CM}$ has been addressed in solid tumors and hematopoietic a

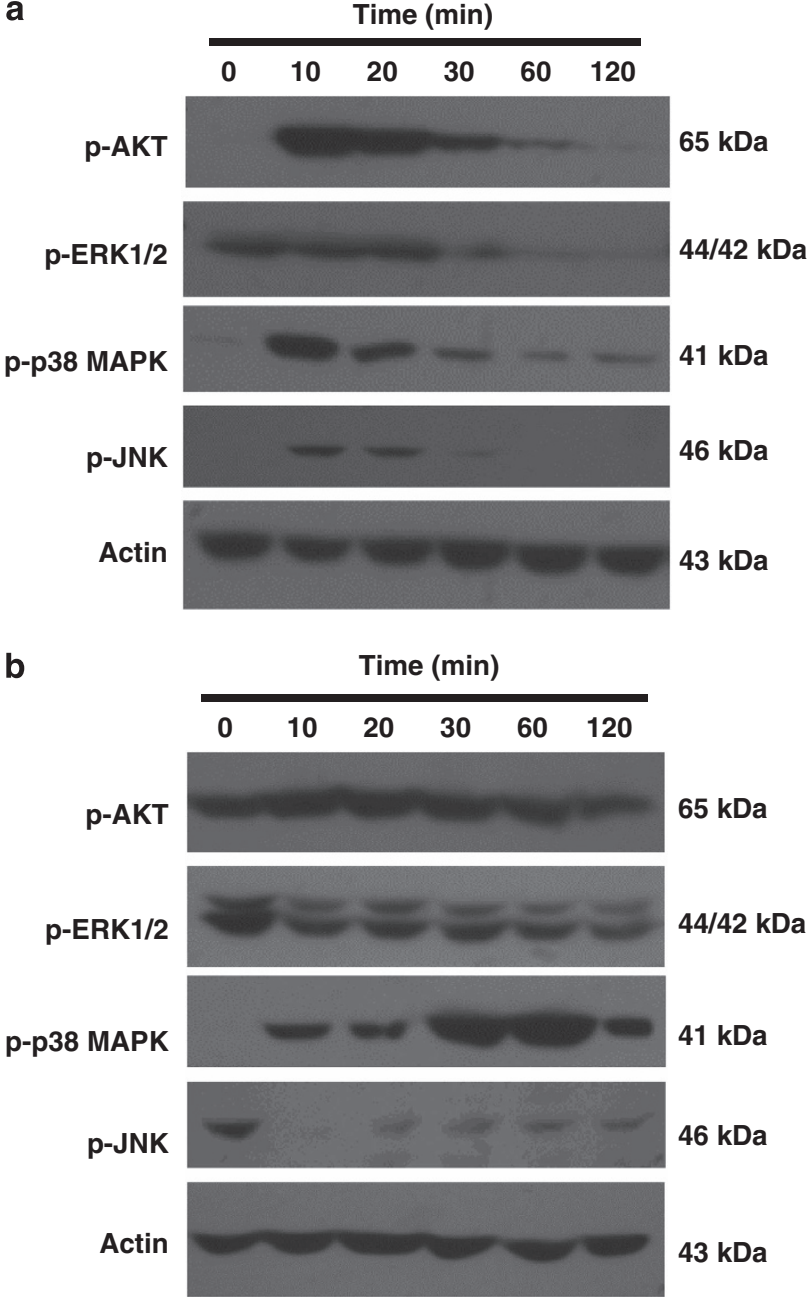

Figure 5 Effects of mycelial fermentation (MF) of CM on signaling profiles in human glioblastoma cells. GBM8401 (a) and U-87MG (b) cells were treated with $1 \mathrm{mg} / \mathrm{ml}$ of MF of CM for the indicated duration, and the lysates were subjected to western blotting detection. The representative result of three independent experiments is shown

cancer. ${ }^{16-19,25}$ In that regard, the activation of effector caspases and upstream initiator caspases has been previously evidenced in many kinds of tumor cells treated with either fermentation or specified constituents from different Cordyceps species, including C. sphecocephala, ${ }^{16}$ C. pruinosa, ${ }^{26}$ C. sinensis, ${ }^{27}$ as well as $\mathrm{CM}^{19,28}$ This study demonstrated that both preparations induced glioblastoma cell apoptosis through caspase- and Bcl-2/Bax-mediated pathways (Figures 3 and 4). In agreement with our finding, the downregulation of antiapoptotic Bcl-2 expression has been noted in Cordyceps extract-treated A549 lung carcinoma cells, ${ }^{25} \mathrm{HeLa}$ cells, ${ }^{26} \mathrm{HepG} 2$ hepatoblastoma cells, ${ }^{16}$ and leukemia cells. ${ }^{27}$ Similar to our results, the fermentation of $\mathrm{CM}$ has been found to induce $\mathrm{Bcl}-2$ downregulation, but not affect Bax protein levels and caspase- 9 activity in apoptotic U937 leukemia cells. ${ }^{28}$ It is worth noting that the treatment with $\mathrm{CM}$ fermentations led to the activation of caspase-8 but 


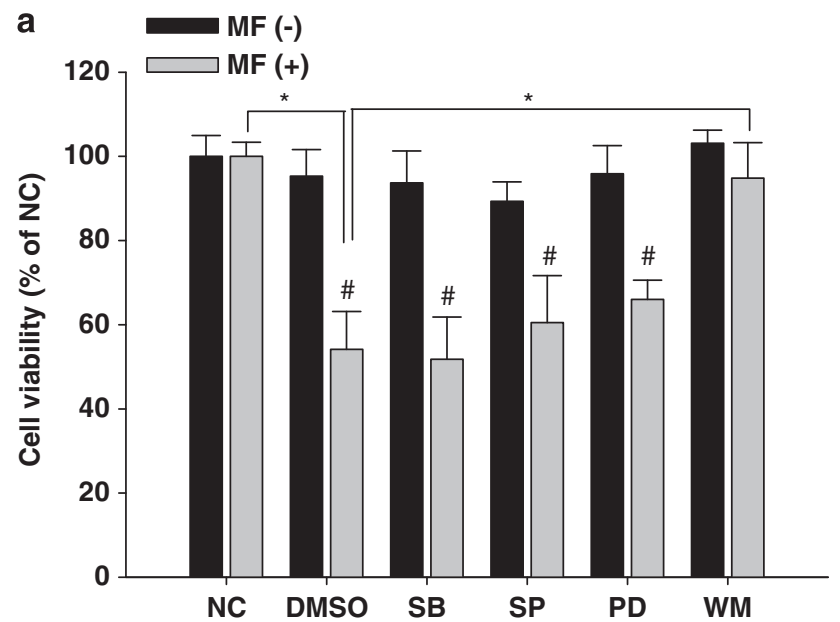

wild-type p53 but mutant PTEN genes. ${ }^{30}$ The discrepancy in genetic background of these two glioblastoma cell lines may constitute the differential response of the cell cycle regulatory machinery. In fact, PTEN is well known to regulate negatively the PI3K/Akt pathway, one of the most important pathways for cell growth, proliferation, and survival. ${ }^{31}$ On the one hand, Akt phosphorylates and activates MDM2, a p53-binding protein that targets $p 53$ for its proteasomal degradation. On the other hand, Akt also phosphorylates and inactivates glycogen synthase kinase-3, resulting in the stabilization of cyclin D1 and the downregulation of p27, a negative regulator of cyclindependent kinases. Conversely, PTEN coordinates the G1 arrest of breast cancer cells by downregulating cyclin D1 via its protein phosphatase activity and upregulating p27 via its lipid phosphatase activity. ${ }^{32}$ Loss of PTEN function results in Akt hyperactivation due to increased concentrations of phosphatidylinositol 3,4,5-triphosphate (PIP3), as reflected by the higher constitutive level of Akt phosphorylation in $\mathrm{U}-87 \mathrm{MG}$ cells than that in GBM8401 cells (Figure 5b). Moreover, cordycepin causes p21 ${ }^{\mathrm{WAF} 1}$-mediated G2/M cell cycle arrest of human bladder cancer T-24 cells bearing the mutant PTEN gene, ${ }^{15}$ while PTEN gene delivery into T-24 cells induced G1 growth arrest. ${ }^{33}$ Therefore, PTEN deficiency is believed to contribute to genomic instability and alteration in multiple cell cycle checkpoints. ${ }^{34}$ This coincides with the finding of CM-induced G1 growth arrest in GBM8401 cells (Table 1).

In the context of the regulatory roles of MAPK signaling mediators in the mechanism of Cordyseps-induced apoptogenesis, a comparison among the signaling profiles elicited by various constituents of $\mathrm{CM}$ or relative species under different scenarios may provide insightful implications. Although methanol extract of $\mathrm{CM}$ has recently been reported to induce IL-8 expression in human lung carcinoma A549 cells via ERK and JNK signaling pathways, ${ }^{35}$ water extract was also found to induce A549 cell apoptosis through both death receptormediated extrinsic and mitochondria-mediated intrinsic pathways. ${ }^{19}$ The significance of ERK in glioblastoma carcinogenesis may be reflected by the constitutive activation of ERK1/2 in both cell lines (Figure 5), while the attenuation of CM fermentation-induced cytotoxicity in U-87MG cells by inhibition of ERK cascade (Figure $6 b$ ) strongly suggests that ERK has a crucial role in the regulation of glioblastoma apoptogenesis. In addition, ERK activity is also involved in the activation of a death receptor-mediated extrinsic pathway, ${ }^{36}$ again highlighting its complex regulatory role in glioblastoma carcinogenesis. In spite of the remarkable CM fermentationtriggered p38 MAPK phosphorylation noted in both glioblastoma cell lines (Figure 5), this signaling activity has been demonstrated to be unrelated to the functioning of the apoptogenic machinery, because the blockade of p38 MAPK activity cannot affect the apoptogenesis (Figure 6). The exact role of p38 MAPK signaling cascade in the induced biological effect requires further elucidation.

Contrary to a previous study in which aqueous extract of $\mathrm{CM}$ induced breast cancer cell apoptosis through Akt inactivation, ${ }^{25}$ the kinase inhibitor pretreatment in this study clearly pointed out that the CM-induced transient Akt activation, at least in part, participated in the inducible apoptogenesis of GBM8401 cells (Figure 6a). In fact, cordycepin was also found 
to activate AMP-activated protein kinase (AMPK), ${ }^{37}$ which is a key energy sensor having a critical and negative role in the regulation of fatty acid synthesis. ${ }^{38}$ Inhibition of fatty acid synthase has recently been demonstrated to induce caspase8-mediated tumor cell apoptosis, but not caspase-9-mediated tumor cell apoptosis. ${ }^{39}$ This again coincides with and supports the observation that only caspase- 8 was activated in apoptotic glioblastoma cells (Figure 3). However, inconsistent with the canonical concept that the activation of Akt pathway exhibits an antiapoptotic effect, our data indicated that the transiently induced Akt phosphorylation contributed to the CM-driven GBM8401 cell apoptosis due to the fact that pretreatment with Akt kinase inhibitor wortmannin unequivocally rescued cell death in GBM8401 cells (Figure 6a), but potentiated cytotoxicity in U-87MG cells (Figure 6b). This differential phenomenon raises the possibility that the upregulated Akt activity might be responsible for AMPK activation and subsequent caspasemediated apoptogenesis and autophagic induction, but not for antiapoptotic signaling. ${ }^{40}$

In the context of the role of PI3K/Akt/mTOR autophagy pathway in oncogenic regulation, Akt as the major player downstream class I PI3K can activate mTOR and lead to inhibition of autophagy. Conversely, class III PI3K can induce autophagy and the class III PI3K inhibitors, such as LY294002 and wortmannin, can repress the autophagy process. In fact, Beclin-1 and class III PI3K, two components of the autophagyinducing complex, have been demonstrated as direct substrates of caspase- 3 and caspase- 8 in response to different inducers of both intrinsic and extrinsic apoptotic pathways. ${ }^{41,42}$ Moreover, the antiapoptotic Bcl-2 protein is known to form complexes with Beclin-1 and inhibits autophagy; thus, it has been proposed as a key cross-talking mediator between apoptosis and autophagy. ${ }^{42}$ In this regard, the $\mathrm{CM}$-triggered $\mathrm{Bcl}-2$ downregulation may also contribute to induction of autophagic cell death. It is noteworthy that cordycepin is more recently demonstrated to induce both apoptosis and autophagy in breast cancer cells. ${ }^{43}$ Consistently, the findings of this study also support that the autophagic induction is most likely involved in the CM-driven glioblastoma cell death. The molecular mechanisms by which CM mycelial fermentation exhibits proapoptogenesis and autophagic induction in glioblastoma cells are schematically proposed in Figure 7.

In conclusion, here we presented that $\mathrm{CM}$ and its myeclial fermentation can halt the cell cycle, stimulate chromosomal DNA breakdown, and ultimately result in both apoptotic and autophagic cell death of cultured glioblastoma cells. The extracellular components obtained by submerged mycelial culture of CM potently inhibited cell proliferation of human glioblastoma GBM8401 and U-87MG cells by inducing growth arrests at the G0/G1 and G2/M phases, respectively. This is the first report describing the antiglioblastoma cell activity derived from the submerged culture of $\mathrm{CM}$. The $\mathrm{CM}$ fermentation could interrupt cell cycle progression of cultured glioblastoma cells through the p53-p21 signaling axis and induce chromosomal DNA disintegration and subsequent apoptosis through $\mathrm{Bcl}-2$ and Bax disequilibrium, caspase activation, as well as autophagic induction. Signaling delineation and kinase pretreatment study mechanistically demonstrated the involvement of PI3K/Akt and MEK1 pathways in CM-driven glioblastoma cytotoxicity. Accordingly, our findings suggest that the mycelia fermentation of $\mathrm{CM}$ may have clinical

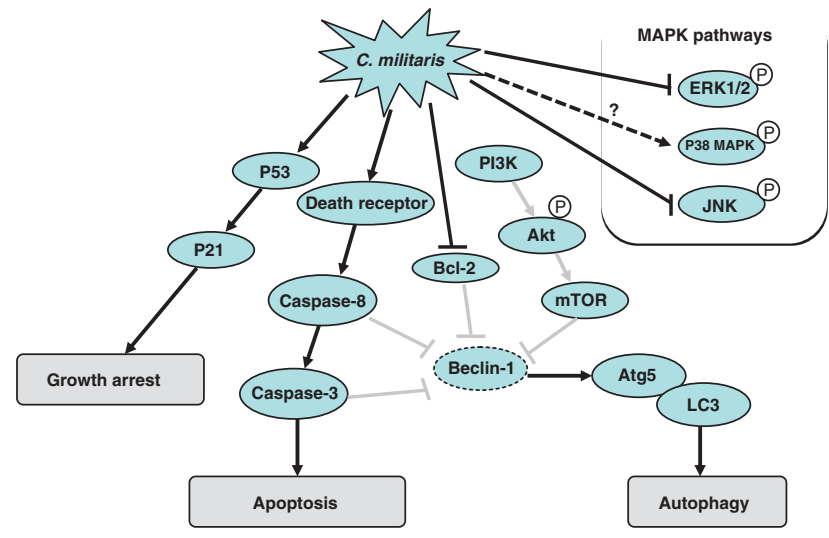

Figure 7 A schematic diagram showing the possible therapeutic mechanisms through which mycelial fermentation of CM either intervenes in cell growth or induces apoptosis and autophagy of human glioblastoma cells. Solid lines in the diagram indicate the findings in this study, while gray lines show the known molecular mechanisms. Abbreviations: ERK1/2, extracellular signal-regulated kinase 1/2; JNK, c-Jun N-terminal kinase; LC3, microtubule-associated protein 1 light chain 3; MAPKs, mitogen-activated protein kinases; mTOR, mammalian target of rapamycin; PI3K, phosphoinositide 3-kinase

therapeutic potential against human glioblastoma and will be clinically useful in the future.

\section{Materials and Methods}

Micro-organ and flask culture conditions. C. militaris (CM, Linnaeus) Link BCRC 32219 (=ATCC 26848) used in this study was obtained from the Biosource Collection and Research Center (BCRC, Hsinchu, Taiwan). The culture medium composition for the fermentation was comprised of $10 \mathrm{~g} / \mathrm{l}$ of dextrose, $3 \mathrm{~g} / \mathrm{l}$ of malt extract, $5 \mathrm{~g} / \mathrm{l}$ of peptone, and $3 \mathrm{~g} / \mathrm{l}$ of yeast extract. The $\mathrm{pH}$ was initially adjusted to 6 , followed by autoclaving. The flask culture experiments were accomplished in $250 \mathrm{ml}$ flasks containing $3 \%(\mathrm{v} / \mathrm{v})$ inoculum of CM and $100 \mathrm{ml}$ of culture medium. The culture was cultivated at $20^{\circ} \mathrm{C}$ in a rotary shaker incubator at 150 r.p.m., and samples were collected at various intervals for analyzing the biomass dry weight, the production of exopolysaccharide, and intracellular polysaccharide. The mycelia biomass and culture supernatants were collected and separated by centrifugation at $10000 \times g$ for $30 \mathrm{~min}$. The centrifuged pellets were then thoroughly rinsed with a large amount of distilled water, followed by lyophilization and dry weight determination. The lyophilized powder was then dissolved in serum-free RPMI or DMEM media and filtered through a $0.22 \mu \mathrm{m}$ filter and stored at $4{ }^{\circ} \mathrm{C}$. All experiments were carried out at least in triplicate and the results were averaged.

Cell culture. Human MCF-7 breast cancer cells (BCRC 60436), mouse 3T3 fibroblasts (BCRC 60071), human GBM8401 (BCRC 60163), and U-87MG (BCRC 60360) glioblastoma cells were purchased from BCRC. 3T3 fibroblasts, MCF-7, and U-87MG cells were cultured in DMEM, unless GBM8401 cells were grown in RPMI 1640. All media were supplemented with $10 \%$ FBS and 1\% antibiotics, including penicillin and streptomycin, and cells were cultured in a humidified incubator containing $5 \% \mathrm{CO}_{2}$ at $37^{\circ} \mathrm{C}$.

Cell viability analysis. Viability of control and treated cells was evaluated using MTT assay in triplicate. Cells $\left(1 \times 10^{4}\right.$ per well) were seeded in 96-well microtiter plates containing $100 \mu \mathrm{l}$ culture medium per well at $24 \mathrm{~h}$ before treatment. After $24 \mathrm{~h}$ of treatment with the test compounds (lyophilized products), cells were incubated at $37^{\circ} \mathrm{C}$ in $200 \mu \mathrm{l}$ MTT solution $(1 \mathrm{mg} / \mathrm{ml})$ for $4 \mathrm{~h}$. After removal of the medium and MTT, $100 \mu$ l of DMSO was added to each well and the assay plate was read at $595 \mathrm{~nm}$ using a microplate reader (Thermo Scientific Basic ELISA Type 354, Thermo Fisher Scientific K.K., Kanagawa, Japan). Absorbance of untreated cells was considered as $100 \%$. 
Flow cytometry. For cell cycle and hypodiploidic DNA analyses, the treated cells were harvested with trypsin, washed with PBS, and fixed in $75 \%$ ethanol for at least $2 \mathrm{~h}$ at $4{ }^{\circ} \mathrm{C}$. Before analysis, the cells were washed once again with PBS, suspended in a cold $0.1 \%(\mathrm{~W} / \mathrm{v})$ sodium citrate solution containing $100 \mu \mathrm{g} / \mathrm{ml}$ RNase A, $50 \mu \mathrm{g} / \mathrm{ml} \mathrm{PI}$, and $0.1 \%$ (v/v) NP-40, and further incubated on ice for $30 \mathrm{~min}$ in the dark. Flow cytometric analyses were carried out using a flow cytometer (FACS Caliber; Becton Dickinson, San Jose, CA, USA), and CellQuest software (Becton-Dickinson) was used to determine the relative DNA content based on the presence of PI-positive red fluorescence. Sub-G1 population was discriminated by plotting PI-positive events in a logistic scale of histogram to estimate the apoptotic cell population. For the analysis of cell cycle distribution, the sub-G1 population was gated out and non-apoptotic cells were shown on a histogram with a linear scale for DNA content. To detect the Annexin V-positive apoptotic cells, the treated cells were trypsinized and fixed in ice-cold methanol. The cells were then subjected to Annexin V-FITC and PI staining according to the manufacturer's instructions (Calbiochem Merck, Darmstadt, Germany). Cell cycle distribution in histogram and Annexin V quadrant analyses were analyzed by using the WinMDI software (designed by Dr. Joseph Trotter, the Scripps Research Institute, USA, version 2.8).

DAPI nuclear staining for chromosomal condensation. Cells were seeded in a $6-\mathrm{cm}$ dish with $2 \mathrm{ml}$ serum medium, which contained $6 \times 10^{5}$ cells. After cells reached $70-80 \%$ confluence, cells were treated with extracts for $24 \mathrm{~h}$ at various doses $(0.5,1,1.5,2$, and $2.5 \mathrm{mg} / \mathrm{ml})$. Cells were fixed with ethanol, washed with PBS, and stained with $2.5 \mu \mathrm{g} / \mathrm{ml}$ DAPI (Sigma-Aldrich China, Shanghai, PR China) solution for $10 \mathrm{~min}$ at room temperature. The cell were washed two more times with PBS and observed under a fluorescent microscopy (Nikon Corporation, Tokyo, Japan). Apoptotic nuclear change is characterized by the varied nuclear size and appearance of chromosomal condensation.

Caspase activity assay. The lysates from the cells with $6 \mathrm{~h}$ of treatment were subjected to assessment of caspase- 3 , caspase- 8 , and caspase- 9 activities by an ApoAlert caspase assay kit (Clontech, Mountain View, CA, USA). The caspase activity was luminometrically measured by Luminoskan Ascent microplate reader (Thermo Scientific, Vienna, VA, USA) and readings were normalized by total protein.

Statistical analysis. All results were expressed as mean \pm standard deviation (S.D.). Each value is the mean of at least three separate experiments. The differences between negative control and treatment groups were analyzed by Student's $t$-test. $P$-values $<0.05$ were declared as significant.

\section{Conflict of Interest}

The authors declare no conflict of interest.

Acknowledgements. This work was financially supported by a grant from I-Shou University, E-Da Hospital, and the National Science Council of Taiwan.

1. Stone R. Last stand for the body snatcher of the himalayas? Science 2008; $322: 1182$.

2. Stone R. Improbable partners aim to bring biotechnology to a himalayan kingdom. Science 2010; 327: 940-941.

3. Koç $Y$, Urbano AG, Sweeney EB, McCaffrey R. Induction of apoptosis by cordycepin in ADA-inhibited TdT-positive leukemia cells. Leukemia 1996; 10: 1019-1024.

4. Zhou X, Gong Z, Su Y, Lin J, Tang K. Cordyceps fungi: natural products, pharmacological functions and developmental products. J Pharm Pharmacol 2009; 61: 279-291.

5. Zhu ZY, Liu N, Si CL, Liu Y, Ding LN et al. Structure and anti-tumor activity of a highmolecular-weight polysaccharide from cultured mycelium of Cordyceps gunnii. Carbohydr Polym 2012; 88: 1072-1076.

6. Dong JZ, Liu MR, Lei C, Zheng XJ, Wang Y. Effects of selenium and light wavelengths on liquid culture of Cordyceps militaris link. Appl Biochem Biotechnol 2012; 166: 2030-2036.

7. Cui JD, Zhang BZ. Comparison of culture methods on exopolysaccharide production in the submerged culture of Cordyceps militaris and process optimization. Lett Appl Microbiol 2011; 52: 123-128

8. Cunningham KG, Manson W, Spring FS, Hutchinson SA. Cordycepin, a metabolic product isolated from cultures of Cordyceps militaris (Linn.) link. Nature 1950; 166: 949.

9. Lee JS, Kwon JS, Won DP, Lee JH, Lee KE, Lee SY et al. Study of macrophage activation and structural characteristics of purified polysaccharide from the fruiting body of Cordyceps militaris. J Microbiol Biotechnol 2010; 20: 1053-1060.
10. Das SK, Masuda M, Sakurai A, Sakakibara M. Medicinal uses of the mushroom Cordyceps militaris: current state and prospects. Fitoterapia 2010; 81: 961-968.

11. Zheng $P, X i a ~ Y, X i a o ~ G$, Xiong C, Hu X, Zhang S et al. Genome sequence of the insect pathogenic fungus Cordyceps militaris, a valued traditional Chinese medicine. Genome Biol 2011; 12: R116.

12. Rao YK, Fang SH, Wu WS, Tzeng YM. Constituents isolated from Cordyceps militaris suppress enhanced inflammatory mediator's production and human cancer cell proliferation. J Ethnopharmacol 2010; 131: 363-367.

13. Wang SH, Yang WB, Liu YC, Chiu YH, Chen CT, Kao PF et al. A potent sphingomyelinase inhibitor from Cordyceps mycelia contributes its cytoprotective effect against oxidative stress in macrophages. J Lipid Res 2011; 52: 471-479.

14. Lee JS, Hong EK. Immunostimulating activity of the polysaccharides isolated from Cordyceps militaris. Int Immunopharmacol 2011; 11: 1226-1233.

15. Lee SJ, Kim SK, Choi WS, Kim WJ, Moon SK. Cordycepin causes p21WAF1-mediated G2/ $\mathrm{M}$ cell-cycle arrest by regulating $\mathrm{c}$-Jun $\mathrm{N}$-terminal kinase activation in human bladder cancer cells. Arch Biochem Biophys 2009; 490: 103-109.

16. Oh JY, Baek YM, Kim SW, Hwang HJ, Hwang HS, Lee SH et al. Apoptosis of human hepatocarcinoma (HepG2) and neuroblastoma (SKN-SH) cells induced by polysaccharides-peptide complexes produced by submerged mycelial culture of an entomopathogenic fungus Cordyceps sphecocephala. J Microbiol Biotechnol 2008; 18: 512-519.

17. Chen Y, Guo H, Du Z, Liu XZ, Che Y, Ye X et al. Ecology-based screen identifies new metabolites from a Cordyceps-colonizing fungus as cancer cell proliferation inhibitors and apoptosis inducers. Cell Prolif 2009; 42: 838-847.

18. Kitamura M, Kato H, Saito Y, Nakajima S, Takahashi S, Johno H et al. Aberrant, differential and bidirectional regulation of the unfolded protein response towards cell survival by $3^{\prime}$ deoxyadenosine. Cell Death Differ 2011; 18: 1876-1888.

19. Park SE, Yoo HS, Jin CY, Hong SH, Lee YW, Kim BW et al. Induction of apoptosis and inhibition of telomerase activity in human lung carcinoma cells by the water extract of Cordyceps militaris. Food Chem Toxicol 2009; 47: 1667-1675.

20. Kellogg VL. Metagenesis in insects. Science 1907; 26: 875-876.

21. Berenbaum MR, Eisner T. Bugs' Bugs. Science 2008; 322: 52-53.

22. Shimkin MB. Reporting on cancer research. CA Cancer J Clin 1967; 17: 94-95.

23. Van Meir EG, Hadjipanayis CG, Norden AD, Shu HK, Wen PY, Olson JJ et al. Exciting new advances in neuro-oncology: the avenue to a cure for malignant glioma. CA Cancer J Clin 2010; 60: 166-193.

24. Mahoney DJ, Lefebvre C, Allan K, Brun J, Sanaei CA, Baird S et al. Virus-tumor interactome screen reveals ER stress response can reprogram resistant cancers for oncolytic virus-triggered caspase-2 cell death. Cancer Cell 2011; 20: 443-456.

25. Jin CY, Kim GY, Choi YH. Induction of apoptosis by aqueous extract of Cordyceps militaris through activation of caspases and inactivation of Akt in human breast cancer MDA-MB231 Cells. J Microbiol Biotechnol 2008; 18: 1997-2003.

26. Kim HG, Song H, Yoon DH, Song BW, Park SM, Sung GH et al. Cordyceps pruinosa extracts induce apoptosis of HeLa cells by a caspase dependent pathway. $J$ Ethnopharmacol 2010; 128: 342-351.

27. Zhang QX, Wu JY. Cordyceps sinensis mycelium extract induces human premyelocytic leukemia cell apoptosis through mitochondrion pathway. Exp Biol Med (Maywood) 2007; 232: 52-57.

28. Park C, Hong SH, Lee JY, Kim GY, Choi BT, Lee YT et al. Growth inhibition of U937 leukemia cells by aqueous extract of Cordyceps militaris through induction of apoptosis. Oncol Rep 2005; 13: 1211-1216.

29. Sayers TJ. Targeting the extrinsic apoptosis signaling pathway for cancer therapy. Cancer Immunol Immunother 2011; 60: 1173-1180.

30. Adachi J, Ohbayashi K, Suzuki T, Sasaki T. Cell cycle arrest and astrocytic differentiation resulting from PTEN expression in glioma cells. J Neurosurg 1999; 91: 822-830.

31. Chu EC, Tarnawski AS. PTEN regulatory functions in tumor suppression and cell biology. Med Sci Monit 2004; 10: RA235-RA241.

32. Weng LP, Brown JL, Eng C. PTEN coordinates G(1) arrest by down-regulating cyclin D1 via its protein phosphatase activity and up-regulating p27 via its lipid phosphatase activity in a breast cancer model. Hum Mol Genet 2001; 10: 599-604.

33. Tanaka M, Koul D, MA Davies, Liebert M, Steck PA, Grossman HB et al. MMAC1/PTEN inhibits cell growth and induces chemosensitivity to doxorubicin in human bladder cancer cells. Oncogene 2000; 19: 5406-5412.

34. Gupta A, Yang Q, Pandita RK, Hunt CR, Xiang T, Misri S et al. Cell cycle checkpoint defects contribute to genomic instability in PTEN deficient cells independent of DNA DSB repair. Cell Cycle 2009; 8: 2198-2210.

35. Han JY, Im J, Choi JN, Lee CH, Park HJ, Park DK et al. Induction of IL-8 expression by Cordyceps militaris grown on germinated soybeans through lipid rafts formation and signaling pathways via ERK and JNK in A549 cells. J Ethnopharmacol 2010; 127: 55-61.

36. Cagnol S, Chambard JC. ERK and cell death: mechanisms of ERK-induced cell death apoptosis, autophagy and senescence. FEBS J 2010; 277: 2-21.

37. Guo P, Kai Q, Gao J, Lian ZQ, Wu CM, Wu CA et al. Cordycepin prevents hyperlipidemia in hamsters fed a high-fat diet via activation of AMP-activated protein kinase. J Pharmacol Sci 2010; 113: 395-403. 
38. Thomson DM, Winder WW. AMP-activated protein kinase control of fat metabolism in skeletal muscle. Acta Physiol (Oxf) 2009; 196: 147-154.

39. Knowles LM, Yang C, Osterman A, Smith JW. Inhibition of fatty-acid synthase induces caspase-8-mediated tumor cell apoptosis by up-regulating DDIT4. J Biol Chem 2008; 283: 31378-31384.

40. Chen S, Rehman SK, Zhang W, Wen A, Yao L, Zhang J et al. Autophagy is a therapeutic target in anticancer drug resistance. Biochim Biophys Acta 2010; 1806: 220-229.

41. Cho DH, Jo YK, Hwang JJ, Lee YM, Roh SA, Kim JC et al. Caspase-mediated cleavage of ATG6/Beclin-1 links apoptosis to autophagy in HeLa cells. Cancer Lett 2009; 274: 95-100.

42. Djavaheri-Mergny M, Maiuri MC, Kroemer G. Cross talk between apoptosis and autophagy by caspase-mediated cleavage of Beclin 1. Oncogene 2010; 29: 1717-1719.
43. Choi S, Lim MH, Kim KM, Jeon BH, Song WO, Kim TW et al. Cordycepin-induced apoptosis and autophagy in breast cancer cells are independent of the estrogen receptor. Toxicol Appl Pharmacol 2011; 257: 165-173.

Cell Death and Disease is an open-access journal published by Nature Publishing Group. This work is licensed under the Creative Commons Attribution-NonCommercialShare Alike 3.0 Unported License. To view a copy of this license, visit http://creativecommons.org/licenses/by-nc-sa/3.0/

Supplementary Information accompanies the paper on Cell Death and Disease website (http://www.nature.com/cddis) 